\title{
Multifaceted Offenders and Minimization of Victims: U.S. National News Media Coverage of Offenders and Victims in Coverage of Filicide
}

\author{
Amy Baumann Grau ${ }^{1}$ \\ Notre Dame of Maryland University, USA
}

\begin{abstract}
There has been more discussion by and from the media in recent years over the issue of domestic violence, this has largely overlooked instances of fatal family violence. This project examines 340 cases of parents or stepparents who killed their children between January 1, 2004, and December 31, 2013 and reported in the U.S. national news media. A content analysis of the news coverage identified themes of positive, negative, and sympathetic portrayals of offenders and victims as well as the minimization of victims. News coverage of offenders depicted them as multifaceted persons with details that could humanize or other offenders while victims were minimized with more focus on the harm done to them than the lives they led. As the focus on offenders occurred in conjunction with the minimization of victims, it is concluded that news media coverage is offender-centric and such media coverage needs to be more balanced in portrayals of victims and offenders to better address and respond to the issue of fatal family violence.
\end{abstract}

KEYWORDS: Filicide, Family Violence, Media Portrayals, Victims, Victimization.

Crimes in the home or relationships have received more media attention in recent years. Despite a greater recognition of the home as a potential site of victimization, family violence has not garnered much attention in the media. When family violence is in the news, the coverage of the crime highlights a pervasive and troubling pattern wherein the focus tends to be on the offender and their crimes without much attention on the victim. Attention remains on the offender through "othering," emphasizing the differences between "normal" people and the criminal "other," and through diminishing actions or humanizing offenders. When coverage focuses on offenders, attention is diverted from victims resulting in a minimization of victims. This minimization casts victims as more of a harmed object instead of a human being who lost their life.

This research focuses on national news media coverage of parents who kill their children, hereafter referred to as filicide. Filicide is a crime that is difficult to ascertain the true extent or frequency of occurrence. This is partly due to underreporting, as there are an unknown number of deaths of children for whom there are no official records, such as children not born in hospitals or children who are unknown homicide victims. Scholars have put forward estimates on the occurrence of filicide. Barnett (2016) estimated nearly two children are killed by a parent every day in the U.S. Official records on family violence in the U.S. have been infrequently updated and rely upon data from police departments. The most recent reports by the Bureau of Justice Statistics on family violence published in 2005 indicates that in 2002, roughly six percent (approximately

${ }^{1}$ Correspondent Author E-Mail: agrau@ndm.edu 
500 ) of 9,102 murder victims in the United States were sons or daughters killed by a parent (Durose et al., 2005).

Given the dearth of official reporting, it is through the news that people learn about filicide. It is thus important to know what can be gleaned from this reporting. Research on news media coverage of filicide has largely focused only on offenders (Barnett, 2016; Deckert, 2019; Little, 2018; Niblock, 2018); there has been less research comparing offenders and victims (Collins, 2016; DiBennardo, 2018). Scholarly attention on victims of crimes has increased (Gruenewald et al., 2013; Pemberton et al., 2019; Walklate et al., 2019), but it is still an underdeveloped field of research. There are no known studies comparing the coverage of filicide offenders and victims. This work advances understandings of media portrayals of filicide by examining the coverage of offenders and their victims in parallel. The extent to which news media coverage of victims and offenders differs, and the specific ways it differs, is an area of research needing more exploration.

To bridge this gap, I examine how media coverage of filicide portrays victims and offenders and how those portrayals focus on offenders through humanizing or othering offenders while minimizing victims. Offenders are intentionally othered to distance offenders from the rest of society, but this othering of offenders is not universal (Barlow, 2015; Williams \& Clarke, 2018). Depictions of some offenders paint them in positive or sympathetic lights, both of which frame filicide as an atypical act by an otherwise good or loving parent. Whether humanized or othered, the focus of media coverage largely remains on the offenders while victims are minimized in coverage, serving as evidence that a crime occurred and affected someone. Previous research on filicide has illustrated the framing of offenders as mad, bad, or sad (Elizabeth, 2016; Nikunen, 2006; Saavedra \& Oliveira, 2017). I broaden that understanding by focusing on the details that portray offenders and victims in negative, positive, or sympathetic ways. These positive and sympathetic portrayals of offenders humanize offenders while negative portrayals other offenders. Media portrayals of victims, however, dehumanize and minimize victims.

\section{Literature Review}

\section{Overview on Filicide}

A growth in research on filicide on a global scale has occurred, both in attempts to understand occurrences and media coverage of the crimes. Numerous articles have attempted to explain the motivation behind the offense (Meyer \& Oberman, 2001; Resnick, 1969), including the recent work of Eriksson et al. (2016) and Léveillée and Doyon (2019). In Quebec, the motivation for male offenders in most cases was retaliation for separation or the consequence of fatal abuse or discipline (Léveillée \& Doyon, 2019). Through interviews with five mothers and nine fathers taken from the Australian Homicide Project, Eriksson et al. (2016) found gendered pathways to filicide through the motivations of offenders and regarding childhood and adulthood adversities. While the motivations of fathers were classified as accidental/discipline, spouse revenge, and acute mental illness, the motivations of mothers were classified as altruism, neglect, and extreme stress.

Others have attempted to identify the offender characteristics that led to filicidal offending. Brown et al. (2018) reviewed Australian research on filicidal offenders. They found that characteristics of offenders differ depending on perpetrator categories of mothers, fathers, mothers and fathers acting together, stepfathers, and mothers and stepfathers acting together. They found that mothers were commonly characterized as mentally ill or as victims of domestic violence. In contrast, fathers and stepfathers were described as having a criminal history or being perpetrators of domestic violence. For all offenders, drug or alcohol abuse was a common experience. Similarly, Dekel et al. $(2018 ; 2020)$ interviewed parents, stepparents, and caregivers who were convicted 
child murderers in South Africa. Dekel et al. (2018) studied offenders with a focus on the parentchild relationship of the offender and their parent(s). They found experiences of poor parenting in childhood and/or adolescence were detrimental for offenders to attain healthy attachment to their children, perpetuating an intergenerational cycle of abuse (Dekel et al., 2018). Using the same sample, Dekel et al. (2020) focused on adversities across four levels: individual (i.e., adverse parenting experiences, substance abuse), family/relationship (i.e., intimate partner violence, sexual violence), community (i.e., gang involvement), and societal (i.e., political experiences of violence) with their findings suggesting child murderers were victims of violence or adversities themselves.

\section{Media Coverage of Filicide}

Looking specifically at studies on the media coverage of filicide, there is a tendency to focus exclusively on female offenders (Barnett, 2016; Cavaglion, 2008; Saavedra \& Oliveira, 2017) or male offenders (Cavaglion, 2009; Little, 2015, 2018). However, there is little discussion on how gender and the gendered understandings of parenthood could influence media coverage. Cavaglion (2008) demonstrated that mothers are covered differently in the Israeli news media based upon their racialized and classed social position. Non-marginalized mothers were portrayed as insane, regardless of evidence suggesting mental illness, and marginalized mothers were portrayed as bad mothers. Barnett (2016) utilized multiple data collections to discuss how mothers who commit infanticide were portrayed, including case studies and filicide coverage across the world. Notably, Barnett (2016) found infanticide was presented as a problem caused by an individual in the majority of stories, particularly those set in industrialized countries. In contrast, infanticide was presented as a part of a larger social problem in stories set in India and China but published by news organizations from the U.K. and Australia.

Research by Naylor (2001) focused on media coverage in Australia focusing on Rosa Richards. Naylor discussed how Richards was portrayed differently across media reporting, with Richards depicted as "a monster" during committal proceedings, yet during trial and sentencing coverage, she was portrayed as an incompetent mother and victim (2001, p. 159). Huckerby (2003) focused on two American women, Andrea Yates and Khoura Her. Huckerby noted differences in language of the coverage with white mothers categorized as mad, falling victim to their biology, while non-white mothers were bad, as individual failures or an example of the collective failure of her minority culture. This disparate framing occurred even though the mothers experienced the same difficulties and frustrations of motherhood. More recently, Saavedra and de Oliveira (2017) reviewed one Portuguese newspaper from 2003 to 2013 and found mothers depicted as one of two types of bad mothers: the fragile mother who is deserving of forgiveness and the perverse mother who is not. Although the newspaper coverage itself did not depict the women as mad, comments left by readers on the daily newspaper's website did show evidence of framing women as mad mothers.

Conversely, media coverage of fathers who have committed acts of family violence, including filicide, demonstrated a more sympathetic portrayal of offenders than that of mothers. Cavaglion (2009) found fathers portrayed as rational actors, regardless of any evidence or diagnosis of mental illness. Elizabeth (2016) examined newspaper representations of two custody abductions and one filicide-suicide in New Zealand. She found a fathers' rights discourse allowed for framing of the men in more sympathetic terms while ignoring relational and social context, such as a history of violence. Fathers involved in custody abductions were more sympathetically framed, while the filicide-suicide father was framed as mad or bad (Elizabeth, 2016). An analysis of radio and television coverage of a familicide-suicide committed by Alan Hawe in Ireland found evidence of decontextualization and exoneration of Hawe in the coverage, such as failing to identify the crime 
as a familicide-suicide and defining the victims by their relationship to Hawe (O' Brien \& Culloty, 2020). Similar to what I find here, O'Brien and Culloty found that "the victims... who merit their own tributes, comment and description, were underrepresented... while disproportionate attention went to their murderer" (2020, p. 12).

Gender is an important component in understanding media coverage of filicide, but there have been few instances in which research has examined both maternal and paternal offenders at the same time (Coorg \& Tounray, 2012; Nikunen, 2006; Niblock, 2018). Coorg and Tounray focused on filicide-suicides involving children with disabilities, finding notable gender differences as $50 \%$ of mothers and $90 \%$ of fathers committed suicide after the filicide. Analyses of murdersuicides in Finnish news focusing on two cases, one mother and one father, further supported by 33 background cases, found men's violence portrayed as against their families. Nikunen suggested that cultural understandings of manhood, not fatherhood, were used to understand men's violence, hence why the violence was described as against the family even though only children were killed. Meanwhile, women's violence was seen as motherly, protecting children from harm or pain; feminine, with women as vain or deceitful; or transgressions of both motherhood and femininity (Nikunen, 2006). Niblock (2018) found fathers were portrayed as heroic and caring, but with some degree of responsibility put on their female partners. Yet, mothers were rarely described in compassionate terms in the coverage of 23 male and 12 female filicide perpetrators in the U.K. Niblock concluded that these reporting practices demonstrate a "troubling recirculation of myths about motherhood and fatherhood" (2018, p. 2463). These reporting practices not only depict myths of parenthood but also help to contribute to the othering of offenders.

\section{Othering}

Drawing from the perspective of symbolic interactionism, the sociological understanding of othering sees it as reproducing inequality directly or indirectly. Schwalbe et al. (2000) identified three types of othering, oppressive, implicit, and defensive othering. This research draws from the idea of oppressive othering, which defines a group as morally inferior. As Schwalbe et al. explain, oppressive othering "commonly entails the overt or subtle assertion of difference as deficit" (2000, p. 423). Four mechanisms are at work in othering: objectification, decontextualization, dehistorization, and deauthorization (Krumer-Nevo \& Sidi, 2012). For this work, objectification and decontextualization are of most importance as objectification reduces people into stereotypes made of inferior traits, and decontextualization removes a behavior from its context. Within crime media, otherness occurs along a continuum ranging from stigmatized others to absolute others (Greer \& Jewkes, 2005). These stigmatized others engage in mundane acts of crime or deviance but come from groups cast as troublesome by the media, culture, or political views. However, absolute others are portrayed to demonstrate "their utter detachment from the social, moral, and cultural universe of ordinary, decent people - their pure and unadulterated evil" (Greer \& Jewkes, 2005, p. 21).

Researchers have demonstrated othering occurring for a variety of offenders such as women (Barlow, 2015), racial/ethnic minorities (Williams \& Clarke, 2018), and sex offenders (McAlinden, 2014; Wardle, 2007). As Wardle states, "when 'evil' is the accepted explanation, there is little tolerance for attempts to contextualize these offenders" (2007, p. 274). "Evil" or othered offenders need no additional explanation of what caused their criminality, and efforts to portray these offenders in other lights are unlikely to be accepted by society as the people are simply "evil." Barlow (2015) described how layers of silencing minimize the voices of female co-offenders and de-prioritize them through othering. This matters as othering of offenders keeps the focus on 
offenders and the strangeness of their crimes while pulling attention from victims and minimizing them.

\section{Coverage on Victims}

Looking at media coverage on victims, research has suggested that coverage can build support for victims. Berns (2004) suggested that media portrayals of domestic violence and their focus on the victims help build support for victims and the programs that benefit them. Others have looked at media coverage or portrayals of homicide victims (Gruenewald et al., 2013; Peelo, 2006). Gruenewald et al. (2013) examined the factors that influenced the newsworthiness of homicide victims by comparing coverage between Hispanic and Black victims and male and female victims. Gruenewald et al. found race/ethnicity and gender influenced the newsworthiness of certain victims, with minority women receiving more coverage than men and female victims receiving more attention if the offender was a stranger. Similarly, Peelo's (2006) work on the portrayal of homicide victims in news coverage discussed the creation of readers as "mediated witnesses." Peelo argued that as mediated witnesses, "we are invited to focus our attention on and emotionally align ourselves with victims, co-victims and survivors of homicide" (2006, p. 163). Such research suggests that coverage is meant to have readers empathize with victims, while others have argued for elevating the voices of victims through narrative victimology. Pemberton et al. discussed how narrative victimology "focuses on how people experience wrongdoing" and further does not make the assumption that victims are passive subjects (2019, p. 393). Walklate et al. demonstrated how characteristics of the victim, as well as other factors, mean "that some narratives count more than others" (2019, p. 211). Walklate et al. (2019) described the case of Rosie Batty, who, in the aftermath of the murder of her 11-year-old son by his father, became a prominent force in Australia changing family violence policies. The aim of elevating voices of victims is admirable, but only survivors can be heard. Thus, it is necessary for others, whether secondary victims or reporters, to carry that torch and speak up for non-surviving victims.

Examinations of media coverage on only victims miss how characteristics of offenders and victims influence coverage. Research comparing victims and offenders has examined newspaper and local television coverage of juveniles (Pollak \& Kubrin, 2007), local newspaper coverage on gender, offending, and victimization in Canada (Collins, 2016), and sexual predators and their victims in Los Angeles (DiBennardo, 2018). According to Pollak and Kubrin (2007), portrayals of victims are intended to create sympathy for the victim. They found coverage of juvenile offenders in Washington, D.C. portrayed their crimes as irrational and senseless, but portrayals of juvenile victims "used several tactics to heighten victim innocence including focusing on the extent of the victim's injuries and highlighting the victim's positive attributes" (Pollak \& Kubrin, 2007, p. 74). Not all victims are thought of as deserving sympathy as Collins (2016) found with female victims described as good victims, deserving of sympathy, or bad victims, who were not. Notably, these bad victims were primarily poor and from minority groups. Collins also found that female offenders were more likely to be dehumanized when the victim was female. Gender and age have also been found to be influential on coverage with sexual predators as DiBennardo found the "media construct and reinforce hierarchized victimhood using child victims, and use child victim narratives to dehumanize" while adult victims are framed as responsible for their victimization (2018, p. 6). Although these results are on different offender populations, it is clear that characteristics of victims and offenders are influential on coverage and who is portrayed sympathetically. 


\section{Social Construction of Reality}

The theoretical underpinnings of this project are social constructionism and media expression theory. Social constructionism focused on the development of objective and subjective reality which is constructed through interactions with others (Berger \& Luckmann, 1967). Through interactions, knowledge is constructed. That knowledge is influenced by one's locations and interactions in the social world. Language constructs reality as typified experiences that create categories to be shared. Although Berger and Luckmann discussed the social construction of reality through face-to-face experiences, the idea applies to media. The media itself is an agent which constructs reality and exerts social control. This application of social control can be seen through othering as described above. Further, as Tuchman (1978) demonstrated, the media chooses what stories to tell and what information is shared, thus constructing knowledge and reality. The creation and sharing of various images and meanings contribute to othering as some social artifacts are deemed desirable while others are undesirable.

I use Mulder's (2006) media expression theory to support the application of social constructionism to media as communication is an exchange of information. The media further are the agent through which this information is exchanged, and the media influence both sender and receiver (Mulder, 2006). Mulder identifies three levels of media expression: information, meaning, and the effects of information or meaning. Effects of meaning refers to the social nature of the media or how the meaning that is sent influences the behavior of the receiver in a way that is desired by the sender. Combining these theories, I argue that the media construct a message with a desired meaning behind it. This desired meaning can be seen through the presentation of socially desirable and undesirable roles and behaviors, such as excusing or othering various criminal offenders.

As one's location and interactions shape knowledge, it is vital to provide the context for this research. Creswell and Poth (2017) identify five evaluation standards for case study research. The first two of those evaluation standards, identification of the study cases and case selection, are discussed in the methods. Description of cases and reporting of generalizations will occur in the results and discussion sections. The fifth standard is researcher reflexivity, discussed here. My sociological perspective, particularly in wanting to understand how the media shape understandings of crime and family violence, influences this research. My view that not enough attention has been on victims and the treatment of victims, whether that be by the criminal justice system, media, or scholarly research further influences this research. Thus, my intention is to examine the disparate coverage of offenders and victims and note some of the impacts of this disparate coverage.

\section{Methods}

I collected the news stories used for this work through the Newsbank, Access World News database. As of this writing, Newsbank contains 5,677 different news sources from around the world, but I restricted the database to only U.S. national newspapers and newswires. This limited the available sources to 18 newspapers and 97 newswires and articles in English. These limitations allowed me to search for stories that had the potential to be published across the entire U.S. It worth noting a story being included in a national newswire or newspaper does not mean that the story would be published in all news sources across the U.S. It is beyond the scope of this research to determine the extent to which a story was successfully published across the nation. Newsbank presents articles in an archive format. Meaning the article as it appeared in print is unavailable. This archive format does not include any photographs published with the article; however, captions of the photograph were included in the archived articles. Given the search terms used to find eligible stories, I found stories in 11 newspapers or newswires. The distribution of stories by 
newspaper/newswire was $232(80 \%)$ reported by the Associated Press (AP), 38 (12\%) from United Press International (UPI), 13 (4\%) from one of nine other eligible newspapers or newswires, and $10(3 \%)$ from a combination of those news sources. Creswell and Poth (2017) specify that case studies require triangulation. While I did not triangulate each specific event, multiple national newswires and newspapers were used and the themes discussed in this research were not isolated to one particular news media source.

I searched the database for news stories on filicide reported from January 1, 2004, to December 31, 2013, using 114 different search terms. The complete list of search terms is available from the author. Any article from any section of the news was included in this analysis. I used quotation marks around search terms to limit the number of extraneous, non-crime articles. The variety of search terms encompassed terms to specify a relationship between offender and victim (i.e., daughter, foster child, stepson), stage of life of victim (i.e., baby, teenager), and crime-related terms (i.e., homicide, kill, murder). The search terms thus collected acts of family violence beyond acts of filicide. I retained those articles but excluded them from this analysis.

There were 4,276 results, averaging 37.51 results per search term. Searches captured some stories multiple times. In instances of duplication, I removed stories that were word for word the same but retained if there was any difference. The articles in this analysis were restricted to events occurring between January 1, 2004 and December 31, 2013. In cases in which the year the crime occurred was unclear, I searched for other stories, not included in the data set nor used in any other way, to clarify the year of the crime to ensure that all cases occurred between 2004 and 2013. I excluded experiences of victimization that occurred prior to 2004 but published between 2004 and 2013 to maintain a consistent time frame. Stories in which the relationship between offender and victim was not that of a parent/child or in which there was no language indicating a parent/child relationship were removed. Adoptive and stepparents remained as these persons were a part of parent/child relationships with the victim(s); however, foster parents were excluded as the permanency of the relationship could not be determined. Two instances of joint partners were removed as the permanency of the relationship between victim and offender could not be established as only one of the offenders was the parent of the victim. I excluded accidental deaths, including car accidents, from the analysis as differences between accidental deaths and intentional or neglectful deaths are beyond the scope of this project.

After removing the excluded cases, this research includes 530 articles, representing 298 offenders and 323 victims in 290 filicide events. I saved screenshots for each story to preserve a record and all images are available from the author. Stories in which multiple offenders were identified were divided by the number of offenders to ensure that no story was counted multiple times. The number of stories per filicide offense ranged from 0.33 to 20, with a mean of 1.77 stories. The majority (64\%) of offenders had one story about them. I read each story a minimum of three times to ensure that it met the criteria for inclusion and to be coded and categorized. The first reading ensured that the article met the inclusion criteria and to record preliminary identification of items of interest, such as name, age, and gender of offenders and victims; and news media coverage information such as date of first publication, duration of coverage, and publication source. Thereafter, I engaged in a content analysis using open and axial coding. This content analysis examined manifest content, countable elements, and latent content, the meaning conveyed (Lune \& Berg, 2017). According to Lune and Berg, the purpose of open coding is to "open inquiry widely" and to "find meanings that are present in the text or supported by it" (2017, p. 182). Using the basic guidelines outlined by Strauss (1987), the data were asked a set of specific and consistent questions and analyzed minutely. The questions asked focused on the details presented in the story, including the facts of the reporting and case, and the details provided about offender and victim. With the major themes identified, I then engaged in a second round of coding 
to reexamine all stories to identify more evidence of and nuance within the themes. After open coding, I engaged in axial coding, an intensive coding of one category, to identify subcategories or subdivisions within the larger themes identified through open coding (Lune \& Berg, 2017).

I created variables in SPSS to record the evidence of positive, negative, and sympathetic portrayals of offenders and victims. The positive, negative, and sympathetic themes and variables identified here were influenced by prior research such as Cavaglion $(2008,2009)$ and Saavedra and Oliveira (2017), in which filicidal parents were labeled as mad, bad, or sad. While such terms have been common in prior research, I used the more expansive terms of positive, negative, and sympathetic to encapsulate depictions of offenders more broadly. I created three variables for each portrayal type. The first variable was dummy coded, indicating the presence (1) or absence (0) of the type of descriptor. The second variable recorded the date of the story or stories in which the descriptors appeared. Finally, the third variable provided a summary of the positive, negative, or sympathetic description. I recorded stories as having statements as offender positive when prosocial details or positively valued terms about the offender were provided, such as mentions of an offender's occupation or the offender being a kind or loving person. Occupation has previously been identified by Collins (2016) as a way to marginalize offenders; however, here, occupation was included as a positive descriptor with the understanding of it as a pro-social identity in the person's life beyond that of parent or offender. Statements were coded as being offender negative when they stressed anti-social details or used negatively valued terms, such as details about the offender's prior criminal record or terms like evil. Stories were recorded as sympathetic to the offender when details were included in the story that could mitigate the offense, such as descriptions of the offender having a mental illness or mentions of the offender apologizing or acting remorseful.

The descriptions of victims were broken down into two groups. The first was to record if information about the victim that identified the gender, age, and name of the victim(s) were provided. Gender, age, and name variables first included dummy coded variables to record the presence (1) or absence (0) of identifying information. Age was determined by either explicit reference to an age (i.e., 8-year-old) or stage of life (i.e., toddler). Gender was identified through gender-specific pronouns or terms like daughter or son. Name was identified through explicit mention of the victim by first or first and last name. I then created a fourth variable, victim not described, to encapsulate instances in which the gender, age, and name of the victim were not provided. I created the victim not described variable by computing a new variable by adding together the name, age, and gender dummy-coded variables with a zero indicating victim not described and values greater than or equal to one demarking the presence of the name, age, and/or gender of the victim. To further study the portrayals of victims, I created variables to capture information regarding positive, negative, or sympathetic portrayals of victims. Like with offenders, I created three variables for each type to measure the presence or absence of the descriptor type, the date(s) when this coverage occurred, and a summary of the evidence. Stories were recorded as being victim positive when they stressed specific details about the lives of the victims in positively valued ways, such as being honor students, being a good child, or a blessing. Stories were recorded as victim negative when details were provided about the victim that were negative, such as a criminal record or gang involvement. Stories were recorded as victim sympathetic when additional details about the victim were provided that humanized the victim, like prior experiences of abuse or medical conditions. 


\section{Results}

This analysis consists of 290 victimization events committed by 162 men and 136 women, ranging in age from 17 to 86 with a mean age of 34.41 years. Of the 298 offenders, 154 men acted alone, 128 women acted alone, and 16 persons were jointly a part of the murder of a child (eight men and eight women). There were 323 victims, 167 male, 140 female, and 16 without a gender identified. The race of offenders and victims was not specified in the written portion of the articles. Table 1 shows the distribution of stories by offender type and gender of victim.

Table 1

Distribution of Stories by Type of Offenders and Gender of Victims

Distribution of Stories $\quad$ Victims

\begin{tabular}{|c|c|c|c|c|}
\hline & \\
\hline & Male & Female & Both & Unidentified \\
\hline & \multicolumn{4}{|c|}{ Male Offenders } \\
\hline Number of Stories & 82 & 62 & 5 & 5 \\
\hline Mean Number of Stories & 1.45 & 1.89 & 1.20 & 1.40 \\
\hline Standard Deviation & 1.04 & 1.62 & 0.45 & 2.03 \\
\hline \multirow[t]{2}{*}{ Range } & $1-5$ & $1-8$ & $1-2$ & $0.33-5$ \\
\hline & \multicolumn{4}{|c|}{ Female Offenders } \\
\hline Number of Stories & 66 & 51 & 4 & 7 \\
\hline Mean Number of Stories & 1.80 & 2.20 & 4.50 & 1.71 \\
\hline Standard Deviation & 2.50 & 2.46 & 3.00 & 0.76 \\
\hline \multirow[t]{2}{*}{ Range } & $1-20$ & $1-13$ & $2-8$ & $1-3$ \\
\hline & \multicolumn{4}{|c|}{ Joint Offenders } \\
\hline Number of Stories & 8 & 8 & & \\
\hline Mean Number of Stories & 0.63 & 1.88 & & \\
\hline Standard Deviation & 0.23 & 1.69 & & \\
\hline Range & $0.50-1$ & $0.50-5$ & & \\
\hline
\end{tabular}

\section{Positive Portrayals}

Examining descriptors qualitatively amplifies the differences in portrayals between offenders and victims. Victims were described positively in $19(6 \%)$ out of the 298 cases, and often these descriptors focused on education-related details, such as Jeanette Maples, who was homeschooled, or Corinne Peters, who was planning on attending the University of Texas. Meanwhile, offenders were described positively in twice as many cases, 40 cases (13\%). Offenders were described by their careers, such as carpenter Clarence Butterfield, youth pastor Adrian Estrada, or teacher of the year Mary Ellen Moffitt. Others were described positively like Lindsey Lowe, who was described as a loving friend and daughter; "all-around person" Larry Meriwether, or Kirsten Vanderline, who "never acted anything but loving to the baby" (AP, 2007c, para. 11; 
Thompson, 2004, para. 4). Female offenders had slightly higher rates of positive descriptions at $16 \%$ compared to $12 \%$ for male offenders.

The cases of Margaret Jensvold and William Lash III demonstrate similarities in the positive portrayals of mothers and fathers. In 2011, Jensvold shot her 13-year-old son, Ben Barnhard, before killing herself. Jensvold was described as "a Johns Hopkins-educated psychiatrist specializing in women's health" and "a protective mother" (Tucker \& Associated Press, 2011, para. 12 \& 13). After a domestic dispute with his wife, William Lash III barricaded himself with his son, William IV. Lash III was described as "a law professor at George Mason University and a former assistant secretary of commerce" who "was devoted to his son and often took him to National's games" (AP, 2006, para. 2 \& 5). For both of these offenders, occupational and educational references and descriptions of them as loving parents were employed. These details humanize them and present them as more than offenders. They are educated, successful people who cared for their children, the opposite of the othering some offenders experienced.

\section{Positive Parents and People}

While both victim positive and offender positive descriptors were often achievementfocused, offender positive details also spoke to their relationships with the family. In nine of the 40 offender positive cases, descriptors focused on positive parenting or family life details, such as doting father Miguel Matias or good mom Gail Coontz. In November of 2009, Jamar Pinkey Sr. reportedly forced his 15-year-old son, Jamar Pinkey Jr., to strip naked, took him to a vacant lot, and shot him once in the head after learning the boy had sexual contact with his 3-year-old halfsister. A neighbor described Pinkey Sr. as "a friendly, attentive father of three who is often seen working on his house" and that "he's good with kids in the neighborhood. He helps with the kids. He buys them ice cream" (Battaglia, \& Angel, 2009, para. 28 \& 29). These descriptions of Pinkey, coupled with killing one of his children for harming one of their siblings, demonstrates the multifaceted portrayals of offenders with complex and convoluted lives.

In $16(40 \%)$ of the 40 offender positive cases, descriptions of the offender used emotionand value-laden language such as being good, loving, or kind-hearted. In 2013, Muni Savyon shot his son, Joshua, 9, in the back of the head and then five more times before turning the gun on himself during a supervised visit at a YWCA. Savyon's ex-wife, who was not the mother of Joshua, described him as a "kind-hearted person," further saying, "he was nonviolent. He would try to help anyone he could. He was a really nice guy"" (Father kills son, himself at YWCA offices in NH, 2013, para. 7 \& 8). Savyon's Rabbi told reporters that "'he had no idea that Savyon was capable of violence, much less harming his own son"' (Father kills son, himself at YWCA offices in NH, 2013, para. 16). These details, from a variety of persons who knew the offender, paint Savyon in a very different light juxtaposing the kind-hearted, non-violent man they knew with the man threatening to kill himself and others before ultimately doing so.

\section{Negative Portrayals}

Negative descriptors of offenders occurred in 105 (35\%) cases, while negative descriptions of victims occurred in only 10 cases $(3 \%)$. Male and female offenders were described at similar rates, with $36 \%$ of male offenders and $33 \%$ of female offenders described negatively. Negative descriptors of offenders fell into three major groups. The first group of negative descriptors was related to their crimes or actions shortly before or after the crime, present in 41 cases. The second grouping included details on alcohol or drug use and abuse, which occurred in 20 cases. The third group of negative descriptors included 25 cases questioning the character of offenders. 
Language such as evil or monster was infrequently used and seemingly unrelated to the heinousness of the crime. Randal Randrup's ex-wife described him as “evil, cold, self-serving, and calculating" (AP, Hawaii Tribune-Herald, 2009, para. 5). In December 2008, Randrup shot his 27year-old son, Chris, allegedly because his son was beating him. The day after the shooting, Chris's nude body was found wrapped in a blanket at the bottom of a cliff. The "evil" description of Randrup stands in contrast to Christina Beltran, who was not described as evil despite the severity of her offense. On July 6, 2007, Beltran allegedly threw her 5-year-old daughter, Evelyn, to the ground for being disobedient. The AP (2007b) reports,

That action caused the girl's head to hit the floor, after which the mother is alleged to have jumped on the girl and struck her several times about the head and face and repeatedly slammed her head against the floor. (para. 3).

It is notable evil or bad were used infrequently, given this being a common theme in other works (Cavaglion, 2008, 2009; Saavedra \& Oliveira, 2017)

\section{Descriptions of Offender's Actions Before or After the Crimes}

The first subtype of negative descriptors provided descriptions about the crimes themselves or the offender's actions before or after the crimes. This was present in 41 (39\%) of the 105 negative descriptor cases. As the articles examined here are crime stories, these negative descriptors are more than just facts about what happened that resulted in the death of a child. In 2008, James Dickerson beat his 7-year-old son to death with a broom handle. A pathologist stated the "injuries were consistent with a car hitting a human at $35 \mathrm{mph}$ " (AP, 2010, para. 4). Details about the actions of Lester Hobbs paint a picture of the years-long abuse his stepdaughter, Aja, experienced. In March 2010, Hobbs was found dead from an apparent suicide after killing his wife and Aja. Articles reported seven allegations of abuse and neglect before Aja's death and how Hobbs treated her, such as slashing her mattress and sheets with a knife, throwing lit firecrackers to awaken her, and having her take baths with him. Reporting on Gabriel Armandariz detailed how he sent his ex-girlfriend a text photo that appeared to show their dead infant son before the boy and his brother were found deceased. The analogy used to describe the harm caused by Dickerson, the multiple details about the years of abuse Hobbs leveled against his stepdaughter, and the description of Armandariz's text message are all additional details beyond the facts of the crime which drive home the heinousness or maliciousness of the offense or offender.

\section{Alcohol or Drug Use and Abuse}

Second of the negative descriptor subtypes mentioned alcohol or drug use and abuse which was present in 20 (19\%) of the 105 negative descriptor cases. Megan Patria gave birth in December 2005 to a full-term baby, put the baby in a toilet, and later, believing the child was dead, put the child in a bag. Patria was described as having attempted to miscarry "by smoking, drinking alcohol, and jokingly asking a friend to hit her" (AP, 2007a, para. 5). For John Violette, a diagnosed paranoid schizophrenic, previous drug use was mentioned as a potential source of his mental breakdown. Coverage on Christopher Payne described how the jury would hear of his past drug use as "prosecutors allege that Payne was so strung out on drugs that he spent all his money on them and let his children starve" (AP, Tucson Citizen, 2009, para. 6). Like the first grouping of 
negative descriptors, these descriptors highlight the failure of these persons to care and provide for their children appropriately.

\section{Negative Character}

Third of the negative descriptor subtypes negatively describe the offenders' character, occurring in 25 of 105 cases (24\%). Details such as prior arrests, allegations of domestic violence, and visits from child protective services were included in this subtype, but these negative descriptors also appealed to morality. In 2008, Neil Entwistle was convicted for the 2006 murder of his wife, Rachel, and their 9-month-old daughter, Lillian Rose. Reporters described him as in debt, unable to find a job, and having several failed internet businesses but also as an unfaithful spouse who "trolled the Internet for local escorts and joined an online swingers' site" (Lavoie, 2011, para. 18). Similarly, stories described Lindsey Lowe with a multitude of negative attributes. In 2011, Lowe gave birth to twin boys in her parent's home and then reportedly smothered the babies before putting them in a laundry basket. Coverage of Lowe's case mentioned details such as cheating on her fiancé, testing positive for a benzodiazepine drug, taking medications for which she did not have a prescription, having accessed pornographic websites in the month before giving birth, and the judge presiding over her case calling her "untruthful and selfish" (Loller, 2013, para. 1).

Across these subtypes of negative descriptors, there was a shared experience of oppressive othering as the actions are incongruent with the cultural expectations of parents and caregivers by hinting at their character and inability to live up to traditional family expectations. Even without language of evil or monster, these negative descriptors demonstrate the numerous ways in which filicidal offenders failed as parents, whether that be through acts of violence, drug or alcohol use and abuse, or depicting them as immoral.

\section{Sympathetic Portrayals}

Across the 298 cases, 59 (20\%) had offender sympathetic details. These sympathetic details varied greatly from case to case; however, a few themes emerged. Of the 59 cases with offender sympathetic details, $41(69 \%)$ spoke of personal problems that the offender was facing ranging from financial difficulties (6), mental health issues (11), suicidal thoughts or actions (5), family issues (16), and health issues (3). Family issues ranged from a recent or impending break-up or divorce (6), domestic violence (3), and the death of a loved one (3). Notably, news media coverage of family issues included ones that had happened shortly before the crime and ones that occurred years before.

China Arnold and Jayne Peters both had experiences of loss mentioned within the coverage of their crimes. China Arnold was convicted of aggravated murder in the 2005 microwave death of her 28-day-old daughter, Paris Talley. Attorneys mentioned that Arnold had been a Girl Scout and that "her father died when she was young" (AP \& Hannah, 2008, para. 10). In 2010, Jayne Peters shot herself and her 19-year-old daughter, Corrine, in a murder-suicide. Details about the Peters family told that there were no signs of strain between the mother and daughter and mentioned the loss of husband and father, Donald Peters, from cancer in 2008. For Peters, the loss of her husband helps to explain why a family that seemingly has a nice life in their "sprawling upscale home" would end in a murder-suicide (Perez, 2010, para. 1). Conversely, details about China Arnold, such as her history of being a Girl Scout and experiencing the death of her father early in life, were undercut by the prosecuting attorney as the experiences do "not outweigh the seriousness of the crime" (AP \& Hannah, 2008, para. 10). Numerous factors likely influenced how Arnold and Peters 
were discussed, such as differences in the ages of their victims, how the children were killed, and that Peters committed suicide. However, these differences highlight how similar experiences are used to understand offenders in vastly different ways.

\section{Minimization of Victims}

Despite the rise of narrative victimology and greater attention to victims, this research does not find evidence of an increased focus on victims in the news media. Victims are seldom the focus on the news story with far more attention devoted to offenders, in both positive and negative ways. There were noticeable differences between portrayals of victims and offenders across the 298 cases. Descriptions of victims tended to focus on factual or informational data about the victim. For victims, $97 \%$ had their gender identified, $94 \%$ had their age identified, and $79 \%$ were identified by name. In comparison, $100 \%$ of offenders were identified by name and gender, while $90 \%$ had their age identified. It is unknown to what degree journalistic practices may have influenced the lack of information available about victims as those practices often dictate that identifying information about minors be withheld to protect their identities and that families are notified before names of victims are published. Journalists themselves believe death reporting is an essential part of the news that allows for the news to warn of dangers in society, gives relatives a place to pay tribute to victims, and for community entitlement to be informed about area events (Duncan \& Newton, 2012). Duncan and Newtown state, "when a tragedy is newsworthy... there is a need for the loss to be acknowledged and for the family to be part of the tribute article" $(2012, \mathrm{p}$. 7). The minimization of victims occurs due to a reporting focus on offenders and treating victims as objects.

\section{Focus on Offender}

Coverage of the infamous Casey Anthony case further highlights how the news media can obfuscate the victim and retain focus on the offender. There were 13 stories from December 2008 to August 2011 on Anthony, who was eventually acquitted in the death of her daughter, Caylee. The coverage of Anthony included stories that were tangential to her case, such as Anthony suffering minor injuries from entangled hand and leg restraints and a fair that had created, but ultimately dismantled, a dunking booth of her. Despite almost three years of reporting, little was said about Caylee beyond identifying information and the hypothesized causes of death put forward by the prosecution and defense. In all of the coverage, the most victim-oriented phrase came from Jose Baez, Anthony's attorney, during a press conference after her acquittal, who said, "Caylee has passed on far, far too soon" (Hightower \& AP, 2011, para. 7).

This lack of focus on victims was evident in cases that did not have prolonged coverage, too. Such as Tonya Brown, who was arrested for the murder after police "found the body of a newborn in a trash receptacle", and Mardala Derival and Mackenson Dantus, who allegedly "killed their 3-month-old child by using vodka to help the baby sleep" (AP, 2008, para. 1; UPI News Service, 2008, para. 1). Older children also had limited details provided, like the unnamed boy beaten to death for breaking a toy by James Dickerson or the unnamed daughter suffocated by her father, Demetrius Goodwin. It was more common for there to be details provided about the experience of victimization through descriptions of the victim's condition at the time of death than for there to be descriptions of them as persons. 


\section{Victim as Object}

Looking at the depictions of victims across the 298 cases, there were 19 cases with positive details provided, 10 cases with negative details, and 32 cases with sympathetic details. However, in $91(31 \%)$ cases, additional details were provided about the condition of the victim(s) after their death. These details often described the injuries that the victim suffered leading up to or causing their death or the placement of the body after the crime(s) occurred. The relative abundance of details about the condition of the victim(s) is notable as such details treat the victim as an object harmed by offenders. The focus remains on the actions of the offender and the death and destruction that they caused.

Clarence Butterfield was accused of shooting, suffocating, and torturing his daughter, Rebekah. Eight stories were written about Butterfield over two years, repeatedly treating Rebekah as an object, with only one describing her before her murder. These descriptions described Butterfield as "then wrapping the body in plastic bags and stuffing it in his 5-foot-freezer" and Rebekah as "the badly decomposing body" (AP, 2009a, para. 4; 2009b, para. 4). The coverage of the death of Rebekah was atypical as there was a higher than average number of stories and two years of coverage. Yet, it is telling that even when there is more coverage of a particular case, the focus remains heavily on the offender and relegates the victim as an object.

The descriptions of the condition of the victim varied in sensitivity and degree of detail. Some stories painted vivid pictures of the offender's actions. In 2008, Cesar Rodriguez was sentenced to prison for the death of his 7-year-old stepdaughter, Nixzmary. Her condition was described as "bound to a chair, starved and forced to urinate in a litter box before she was killed with a fatal blow to the head" (AP \& Goldman, 2008, para. 1). The story further relates that "the girl was so malnourished before she died that she weighed only 36 pounds - about half the weight of an average girl that age" (AP \& Goldman, 2008, para. 9). Robin Graham placed her 11-monthold son in scalding water for two hours in 2003. It was reported "police determined the water, which caused second- and third-degree burns over 80 percent of Austin's body, was likely around 130 degrees. Family members... told police Austin's skin was hanging off of his body in many places" (Bowen, 2005, para. 3-4). These descriptions leave readers with easily imaginable visuals of the physical pain caused.

Descriptions of a body's placement after death were sometimes used to show a level of care about the victim or as evidence of hiding their crimes. In 2010, Stacey Pagli strangled her 18-yearold daughter Marissa and "placed her in bed next to a stuffed bear. Asked why, she said, 'Cause I love Marissa"' (Cohen \& Fitz-Gibbon, 2010, para. 21). Similarly, after being drowned or poisoned by their mother, Leatrice Brewer's three children were found in bed in their pajamas. Descriptions of Miguel Matias putting his daughter's body in a boiler or the multiple children placed in garbage bags or a dumpster detailed offender getting rid of bodies. Given the morbid curiosity that often surrounds death, it is not surprising that gruesome or poignant details were provided. Yet, when the most commonly provided details about the victim beyond their name, age, or gender are details that focus on the condition of the body after being victimized, victims are being treated as objects that had things done to them rather than unique individuals who had their lives cut short. This makes it difficult for readers to serve as mediated witnesses as Peelo (2006) described. 
Table 2

Type of Descriptors by Offender

\begin{tabular}{lrrrrrrr}
\hline \multirow{2}{*}{ Type of Descriptor } & \multicolumn{3}{c}{ Offenders } & \multicolumn{5}{c}{ Victims } \\
\cline { 2 - 8 } & Male & Female & Joint & Male & Female & Both & Unidentified \\
\hline Positive & 18 & 21 & 1 & 9 & 8 & 1 & 1 \\
Negative & 55 & 42 & 8 & 3 & 5 & 0 & 2 \\
Sympathetic & 23 & 35 & 1 & 13 & 18 & 1 & 0 \\
Not Described & 78 & 74 & 10 & 137 & 100 & 7 & 10 \\
Sample Size & 154 & 128 & 16 & 156 & 121 & 9 & 12 \\
\hline
\end{tabular}

\section{Neutral Coverage}

This research focuses on the inclusion of descriptors of offenders and victims; however, descriptions were not provided for every offender or victim. Offenders were not described in 136 $(46 \%)$ cases, and victims were not described in $250(84 \%)$ cases. There were $125(42 \%)$ cases in which neither offender nor victim was described. This high occurrence is a function of several things. As the national news media tend to report on breaking news or news that is more extreme, more details and prolonged coverage of cases would occur on the local news level (Collins, 2016). Additionally, 94 (75\%) of these 125 cases appear in only one article, with four of those persons being one of the multiple offenders mentioned. Many (104) of these cases had a duration of coverage lasting only one day. The stories encompassed here were typically the first reporting of the offense alerting the public to a crime that occurred. This means the reporting occurred before any police investigation or trial proceeding, two of the major ways in which details about offenders or victims would be discovered and discussed.

\section{Discussion}

Although instances of filicide account for roughly 500 of the approximately 15,000 homicides that occur annually in the U.S., depictions of filicidal offenders and victims shed light on the issue of family violence and responses to family violence. To reiterate, I aimed to parse out how portrayals offenders and victims differ in the news media coverage of filicide. In this, there is evidence that offenders are portrayed in multifaceted ways. Some are humanized through positive portrayals of them as lawyers, kind people, or loving parents. Sympathetic portrayals also humanized offenders when the offender showed remorse or had a mental illness. Others were demonized or othered through negative portrayals of them as drug addicts, unfaithful partners, or attempting to cause a miscarriage. This offender-centric focus runs counter to prior research and further contributes to the minimization of victims. This supports the work of O' Brien and Culloty (2020), who found that victims are underrepresented and offenders get disproportionate attention. Contrary to Berns (2004) and Peelo (2006), I do not find support that media coverage provides support or allows for the public to serve as mediated witnesses for victims. The lack of attention on victims makes it difficult to see them as anything more than an object harmed. It is challenging to sympathize or emotionally align with a nameless, genderless child. There is limited evidence of coverage being sympathetic towards victims as others have found (Collins, 2016; Pollak \& Kubrin, 2007); however, sympathetic coverage was less likely than non-descriptive coverage.

As the media coverage tends to be offender-centric, not victim-centric, offenders are treated as real people and have their voices heard. Coverage currently implies the importance of victims 
lies in what was done to them, not in the people that they were or the lives that they led. In 250 out of the 298 cases (84\%), victims were not described in positive, negative, or sympathetic ways, meaning that the only things known about the victim are restricted to their victimization. Furthermore, news articles failed to provide the name of victims in 63 cases, the age of victims in 17 cases, and the gender of victims in 10 cases. In five cases no identifying details were provided. The lack of humanizing and identifying details about victims makes them victimized things as opposed to unique individuals that they were. While the victim is still a part of the story, this research indicates that media portrayals of victims tend to relegate the victim as a minor character within the larger story about crime and violence. This is similar to Barlow's (2015) work; although filicide victims cannot speak for themselves, reporters can include quotes or details from surviving family members or serve as the voice for victims themselves (Duncan \& Newton, 2012). Having so little focus on the victim is insidious; it dehumanizes the victim to the point that even basic information such as a victim's name or demographic information are not mentioned. This is not to suggest that news media coverage of crime needs to act as a shrine to victims. However, more balanced coverage that relays the crime, information about the offender, and information about the victim could go a long way in humanizing and contextualizing crime and crime victims. A focus on offenders tells the crime story and, potentially, enables readers to understand the motives of offenders. It becomes more difficult, if not impossible, for readers to serve as mediated witnesses (Peelo, 2006) when the identity of the victim is omitted. Furthermore, failing to provide information about victims does not protect the victims' privacy as they are deceased. Fishman (2017) and Duncan and Newton (2012) note, families of victims may want to have the information about the crime released, including pictures of the dead, to honor the victim or call more attention to the victimization.

It was more common for news media coverage to portray offenders in negative, positive, and sympathetic lights than the victim. Although negative details of offenders were provided the most (35\%), the humanizing of offenders through positive and sympathetic details stands in stark contrast to the lack of details about victims. In 136 cases (46\%), an offender was described in positive, negative, or sympathetic ways, and 34 (11\%) offenders were described in more than one way. The addition of details about the offender, regardless of type, keeps the focus on the offender. At the same time, these descriptors actively contribute to the othering of offenders.

While previous research tends to suggest that filicidal mothers and fathers are framed as bad, mad, or sad (Cavaglion, 2008, 2009; Naylor, 2001; Saavedra \& Oliveira, 2017) and comparisons of male and female offenders find female offenders portrayed as manipulative (Collins, 2016) or male offenders as more sympathetic (Elizabeth, 2016; Little, 2018), I find that mothers and fathers are portrayed positively, negatively, and sympathetically almost equally. Like prior research (Barlow, 2015; Collins, 2016; Greer \& Jewkes, 2005), there is evidence of othering. Jewkes states, "the media stigmatize offenders, sentimentalize victims and sanctify those deemed particularly vulnerable or tragic" (2015, p. 284). It does not seem that media coverage of offenders or victims is as straightforward as Jewkes (2015) suggests as offenders are shown as multifaceted, nuanced persons with positive, negative, and sympathetic attributes, and victims were bodies harmed.

This research may have only looked at the U.S. context, but these findings can translate cross-nationally. Prior research demonstrates commonalities of media portrayals of filicide across cultures with mothers framed as mad, bad, or sad in Australia (Naylor, 2001), Israel (Cavaglion, 2008), Portugal (Saavedra \& Oliveira, 2017), and the U.S. (Huckerby, 2003), while fathers are framed more sympathetically portrayed in Australia (Little, 2018), Israel (Cavaglion, 2009), and New Zealand (Elizabeth, 2016). O' Brien and Culloty (2020) have already demonstrated that news coverage in Ireland is similarly offender-centric and minimizing. More evidence that media 
coverage of filicide is offender-centric and victim minimizing across cultural contexts would give additional weight to understanding filicidal offenders as othered or excused to support cultural understandings of motherhood and fatherhood, especially in racialized and classed ways (Cavaglion, 2008, 2009; Huckerby, 2003). Regardless, it matters in all cultural contexts that crime news can minimize victims when the focus of articles is primarily fixed on the offender.

\section{Limitations and Future Directions}

As this study focused on news media portrayals in the U.S. national news, specifically examining only national newspapers and newswires, this project only speaks to the U.S. national news media coverage. Having a story reported by a national newswire, such as the Associated Press, does not guarantee that national news coverage occurred. Further, by focusing only on news covered by a national newspaper or newswire, the data may be more inclusive of instances of filicide that were unusual, extreme, or otherwise considered to be more newsworthy. Future research should explore news media coverage of family violence on the local news level or compare coverage on the national and local levels to investigate if the experiences of othering of offenders and minimization of victims occur elsewhere.

The use of news coverage from US national newspapers and newswires, as collected by Newsbank, also meant no photographs or other visuals were included with the news story. Following in the path of Wardle (2007) and Fishman (2017), further investigations into the influence of photojournalism and the images selected as visual representations of the news should occur. An analysis of the photos selected of victims and offenders in the news can further parse out differences regarding treatment and portrayals. Furthermore, the written component of news stories masks the race of victims and offenders when race has influenced portrayals of offenders on the news previously. As such, an examination of racial differences in portrayals of victims and offenders is warranted. This line of research has the potential to shed more light on what victims are deemed newsworthy or how race influences details provided about offenders and victims.

\section{Conclusion}

More attention on victims also needs to coincide with less emphasis on offenders. O' Brien and Culloty (2020) argued that favorable or even neutral coverage of offenders exonerates the offender of blame, while Collins (2016) found evidence that certain victims are framed as bad and undeserving of sympathy. News media coverage that defines victims in relation to the offender, privileges offenders over victims, or frames some victims as responsible for their victimization is problematic. Shifting of blame from offender to victim further silences and objectifies victims. The othering of offenders and the treatment of victims within crime news indicates that there is room for improvement in media coverage of filicide. Barnett (2005) suggests that journalists should alter how they cover stories of maternal filicide to write more thorough and accurate coverage. Having more nuanced and balanced coverage of filicide, particularly with more attention to victims, can change the narrative around filicide. Ultimately, more holistic coverage of filicide could help establish a better response to the crime, akin to Berns's (2004) conclusions on domestic violence as a social problem.

As news media coverage can affect change and call attention to social issues, this capability should be more fully utilized. Media coverage of crime can do more than provide "just the facts" on a specific crime that has occurred. Even an additional sentence, which reports the number of filicides that have made the news in a year or providing information on organizations that help families or children in trouble, could go a long way in addressing the issue of filicide. Othering 
parents who harm their children makes filicide seem like an uncommon, unthinkable occurrence. Masking this reality can make it more difficult for struggling parents or parents with mental illnesses to seek the help they need and so may fail to protect children from potential victimization.

\section{References}

AP. (2006, July 15). Ex-commerce dept. official kills son, self. The Associated Press News Service. AP. (2007, October 2). Arundel teen ordered committed after death of newborn, MD. The Associated Press News Service.

AP. (2007, October 24). Death penalty won't be sought for mother who killed daughter, IL. The Associated Press News Service.

AP. (2007, December 9). Man who killed baby daughter was in court that morning, TN. The Associated Press News Service.

AP. (2008, April 12). Mother of infant found in trash charged with murder, KY. The Associated Press News Service.

AP. (2009, April 15). OC man returns to face charges of killing daughter, CA. The Associated Press News Service.

AP. (2009, December 9). Calif. man indicted on charge of killing daughter. The Associated Press News Service.

AP. (2010, March 4). SC father gets life, killed son with broom handle, SC. The Associated Press News Service.

AP, \& Goldman, A. (2008, April 4). NYC man gets up to 29 years in killing of stepdaughter, 7, 4th Ld-Writethru, NY. The Associated Press News Service.

AP, \& Hannah, J. (2008, September 4). Ohio woman in microwave case spared death penalty, 5th Ld-Writethru, OH. The Associated Press News Service.

AP: Hawaii Tribune-Herald. (2009, October 28). Father who killed son gets 2 years in prison, 1st Ld-Writethru, HI. The Associated Press News Service.

AP: Tucson Citizen. (2009, February 26). Jury selected in Tucson child killing trial, 1st LdWritethru, AZ. The Associated Press News Service.

Barlow, C. (2015). Silencing the other: Gendered representations of co-accused women offenders. Howard Journal of Criminal Justice, 54(5), 469-488.

Barnett, B. (2005). Perfect mother or artist of obscenity? Narrative and myth in a qualitative analysis of press coverage of the Andrea Yates murders. Journal of Communication Inquiry, 29(1), 9-29. https://doi.org/10.1177/0196859904270053

Barnett, B. (2016). Motherhood in the media: Infanticide, journalism, and the digital age. Routledge.

Battaglia, T.S. \& Angel, C. (2009, November 19). Mich. man accused of killing son who admitted "inappropriate contact" with toddler. Detroit Free Press.

Berger, P. L., \& Luckmann, T. (1967). The social construction of reality: A treatise in the sociology of knowledge. Anchor Books.

Berns, N. S. (2004). Framing the victim: Domestic violence, media, and social problems. Routledge.

Bowen, B. (2005, June 15). Mother gets 52 years in scalding death. Copley News Service: The Journal Star.

Brown, T., Tyson, D., \& Fernandez Arias, P. (2018). Filicide in Australia. In T. Brown, D. Tyson, \& P. Fernandez Arias (Eds.), When Parents Kill Children: Understanding Filicide (pp. 145-166). Springer International Publishing. https://doi.org/10.1007/978-3-319-63097-7_8 
Cavaglion, G. (2008). Bad, mad or sad? Mothers who kill and press coverage in Israel. Crime, Media, Culture, 4(2), 271-278. https://doi.org/10.1177/1741659008092332

Cavaglion, G. (2009). Fathers who killed and press coverage in Israel. Child Abuse Review, 18, 127-143. https://doi.org/10.1002/car.1028

Cohen, S., \& Fitz-Gibbon, J. (2010, March 19). NY mom says she killed daughter for being "rude." USA Today.

Collins, R. E. (2016). 'Beauty and bullets': A content analysis of female offenders and victims in four Canadian newspapers. Journal of Sociology, 52(2), 296-310. https://doi.org/10.1177/1440783314528594

Coorg, R. \& Tounray, A. (2012). Filicide-suicide involving children with disabilities. Journal of Child Neurology, 28(6), 745-751. https://doi.org/10.1177/0883073812451777

Creswell, J. W., \& Poth, C. N. (2017). Qualitative inquiry and research design: Choosing among five approaches (4th ed.). SAGE.

Deckert, A. (2019). Indigeneity matters: Portrayal of women offenders in New Zealand newspapers: Crime, Media, Culture. https://doi.org/10.1177/1741659019873771

Dekel, B., Abrahams, N., \& Andipatin, M. (2018). Exploring adverse parent-child relationships from the perspective of convicted child murderers: A South African qualitative study. PLOS ONE, 13(5), e0196772. https://doi.org/10.1371/journal.pone.0196772

Dekel, B., Andipatin, M., \& Abrahams, N. (2020). Exploring adversities among parents convicted of killing their children. PLOS ONE, 15(7), e0235812. https://doi.org/10.1371/journal.pone.0235812

DiBennardo, R. A. (2018). Ideal victims and monstrous offenders: How the news media represent sexual predators. Socius: Sociological Research for a Dynamic World, 4. https://doi.org/10.1177/2378023118802512

Duncan, S., \& Newton, J. (2012). Hacking into tragedy: Exploring the ethics of death reporting in the social media age. In The Phone Hacking Scandal Journalism on Trial (pp. 208-220). Abramis.

Durose, M. R., Harlow, C. W., Langan, P. A., Motivans, M., Rantala, R. R., \& Smith, E. L. (2005). Family violence statistics: Including statistics on strangers and acquaintances (June 2005, NCJ 207846). Bureau of Justice Statistics. https://www.bjs.gov/content/pub/pdf/fvs03.pdf

Elizabeth, V. (2016). 'I'd just lose it if there was any more stress in my life': Separated fathers, fathers' rights and the news media. International Journal for Crime, Justice and Social Democracy, 5(2), 107-120. https://doi.org/10.5204/ijcjsd.v5i2.312

Eriksson, L., Mazerolle, P., Wortley, R., \& Johnson, H. (2016). Maternal and paternal filicide: case studies from the Australian homicide project. Child Abuse Review, 25(1), 17-30.

Father kills son, himself at YWCA offices in NH. (2013, August 12). The Associated Press News Service.

Fishman, J. M. (2017). Death makes the news: How the media censor and display the dead. NYU Press.

Greer, C., \& Jewkes, Y. (2005). Extremes of otherness: Media images of social exclusion. Social Justice, 32(1 (99)), 20-31.

Gruenewald, J., Chermack, S. M., \& Pizarro, J. M. (2013). Covering victims in the news: What makes minority homicides newsworthy? Justice Quarterly, 30(5), 755-783. https://doi.org/10.1080/07418825.2011.628945

Hightower, K., \& AP. (2011, July 5). Casey Anthony acquitted of killing daughter. The Associated Press News Service. 
Huckerby, J. (2003). Women who kill their children: Case study and conclusions concerning the differences in the fall from maternal grace by Khoua Her and Andrea Yates. Duke Journal of Gender Law \& Policy, 10, 149-172.

Jewkes, Y. (2015). Media \& crime (3rd edition). SAGE.

Krumer-Nevo, M., \& Sidi, M. (2012). Writing against othering. Qualitative Inquiry, 18(4), 299 309. https://doi.org/10.1177/1077800411433546

Lavoie, D. (2011, June 29). APNewsBreak: Appeal filed in mother- baby killing. Associated Press Archive.

Léveillée, S., \& Doyon, L. (2019). Understanding the motives behind male filicides to better intervene. European Review of Applied Psychology, 69(2), 73-81. https://doi.org/10.1016/j.erap.2019.03.002

Little, J. (2015). "Family violence happens to everybody": Gender, mental health, and violence in Australian media representations of filicide 2010-2014. Continuum: Journal of Media \& Cultural Studies, 29(4), 605-616. https://doi.org/10.1080/10304312.2015.1025366

Little, J. (2018). Filicide, journalism and the 'disempowered man' in three Australian cases 2010 2016: Journalism. https://doi.org/10.1177/1464884918809739

Loller, Travis. (2013, April 26). Tenn. woman gets 51 years in newborn twin deaths. Associated Press: US News Online.

Lune, H., \& Berg, B. L. (2017). Qualitative research methods for the social sciences (Ninth edition). Pearson.

McAlinden, A. M. (2014). Deconstructing victim and offender identities in discourses on child sexual abuse: Hierarchies, blame and the good/evil dialectic. British Journal of Criminology, 54(2), 180-198. https://doi.org/10.1093/bjc/azt070

Meyer, C. L. \& Oberman, M. (2001). Mothers who kill their children: Understanding the acts of moms from Susan Smith to the "prom mom." NYU Press.

Mulder, A. (2006). Media. Theory, Culture \& Society, 23(2-3), 289-296. https://doi.org/10.1177/0263276406062683

Naylor, B. (2001). The "bad mother" in media and legal texts. Social Semiotics, 11(2), 155-176. https://doi.org/10.1080/10350330120018292

Niblock, S. (2018). "He just snapped": Gender narratives of parents killing their children in the UK press. Journalism Studies, 19(16), 2451-2469. https://doi.org/10.1080/1461670X.2017.135011722

Nikunen, M. (2006). Parenthood in murder-suicide news. Idealized fathers and murderous mums. Journal of Scandinavian Studies in Criminology and Crime Prevention, 7, 164-184. https://doi.org/10.1080/14043850601029430

O’ Brien, A., \& Culloty, E. (2020). Reporting familicide-suicide in broadcast media: An Irish case study to inform better practice. Journalism, 146488492097802. https://doi.org/10.1177/1464884920978028

Peelo, M. (2006). Framing homicide narratives in newspapers: Mediated witness and the construction of virtual victimhood. Crime, Media, Culture, 2(2), 159-175. https://doi.org/10.1177/1741659006065404

Pemberton, A., Mulder, E., \& Aarten, P. G. M. (2019). Stories of injustice: Towards a narrative victimology. European Journal of Criminology, 16(4), 391-412. https://doi.org/10.1177/1477370818770843

Perez, E. S. (2010, July 15). Dallas-area mayor apparently kills daughter, self. The Associated Press News Service.

Pollak, J. M. \& Kubrin, C. E. (2007). Crime in the news: How crimes, offenders and victims are portrayed in the media. Journal of Criminal Justice and Popular Culture, 14(1), 59-83. 
Resnick, P. (1969). Child murder by parents: A psychiatric review of filicide. American Journal of Psychiatry, 325-334(3). https://ajp.psychiatryonline.org/doi/abs/10.1176/ajp.126.3.325

Saavedra, L., \& Oliveira, J. M. de. (2017). Transgressing motherhood: Media reports on infanticide. Deviant Behavior, 38(3), 345-355. https://doi.org/10.1080/01639625.2016.1197007

Schwalbe, M., Godwin, S., Holden, D., Schrock, D., Thompson, S., \& Wolkomir, M. (2000). Generic processes in the reproduction of inequality: An interactionist analysis. Social Forces, 79(2), 419-452. https://doi.org/10.2307/2675505

Strauss, A. L. (1987). Qualitative analysis for social scientists. Cambridge University Press. https://doi.org/10.1017/CBO9780511557842

Thompson, C. (2004, May 28). Mother accused of gruesome killing of baby had asked for help two days earlier. Associated Press Archive.

Tuchman, G. (1978). The news net. Social Research, 45(2), 253-276.

Tucker, E., \& Associated Press. (2011, August 8). Md. Mom who killed son agonized over school costs. The Associated Press News Service.

UPI News Service. (2008, August 21). Prosecutors: Vodka remedy killed baby. UPI News Track.

Walklate, S., Maher, J., McCulloch, J., Fitz-Gibbon, K., \& Beavis, K. (2019). Victim stories and victim policy: Is there a case for a narrative victimology?: Crime, Media, Culture, 15(2), 199-215. https://doi.org/10.1177/1741659018760105

Wardle, C. (2007). Monsters and angels: Visual press coverage of child murders in the USA and UK, 1930-2000. Journalism, 8(3), 263-284. https://doi.org/10.1177/1464884907076461

Williams, P., \& Clarke, B. (2018). The black criminal oher as an object of social control. Social Sciences, 7(11), 234. https://doi.org/10.3390/socsci7110234

\section{Notes on Contributor}

Amy Baumann Grau is an Assistant Professor of Criminology at Notre Dame of Maryland University in Baltimore, MD. Her research interests are in media, crime, victimology, family violence, social problems and the intersections of those areas. Future areas of research include the construction of social problems in the media and true crime coverage of family violence. ORCID ID: https://orcid.org/0000-0001-8058-4832

Manuscript received January 29, 2021

Final revision received May 14, 2021

Accepted May 15, 2021 